\title{
Morphological characteristics of origin of superior arterial mesenteric trunk
}

Faculty of Medicine, University "Ovidius” of Constanta

\begin{abstract}
Our study was conducted on a total of 46 CT angiographies, performed on a GE LightSpeed VCT 64-slice CT installation. Benchmarks were followed in relation to the gender of the person examined. The origin of the superior mesenteric artery relative to the spine we found it in a range between T12 vertebra and L1-L2 intervertebral disc. The T12 vertebra origin was localized in 2 cases ( $4.35 \%$ of cases), both in women. Superior mesenteric artery originated at the level of $\mathrm{L} 1$ in $78.26 \%(90.91 \%$ of male cases and in $66.67 \%$ of women cases). In 8 cases (17.39\% of cases) the origin of the superior mesenteric artery was located at the L1L2 intervertebral disc. Endolumenal vertical diameter of the superior mesenteric artery orifice we found it in the range of 5.6 to $10.9 \mathrm{~mm}$ ( 6.9 to $10.9 \mathrm{~mm}$ in men, and 5.6 to $8.6 \mathrm{~mm}$ in women). Horizontal diameter sizes ranged from 4.9 to $9.7 \mathrm{~mm}$, having 6.4 to $9.7 \mathrm{~mm}$ in men and 4.9 to $8.3 \mathrm{~mm}$ in women. Vertical diameter in males was higher in $59.09 \%$ of cases, with differences between 0.1 to $2.4 \mathrm{~mm}$, and in $40.91 \%$ of cases the horizontal diameter was larger with differences between $0,1-2.1$ $\mathrm{mm}$. Vertical diameter in women was higher in $50 \%$ of cases, with differences of 0.1-2.0 mm and the other $50 \%$ the horizontal diameter was larger, with differences ranging from 0.1 to $2.2 \mathrm{~mm}$. The angle that the superior mesenteric artery makes it with the aortic wall we found between 16,60-120,80, males having values between $24,8-120,80$, and in women $16,7-120,80$. The distance between the origin of the superior mesenteric artery and celiac trunk we found it between 5.0 and $16.5 \mathrm{~mm}$. males

Cosmin Niscoveanu
\end{abstract}

Mircea cel Batran, 108,

Constanta, Romania

email : cosmin_niscoveanu@yahoo.com

phone: +40726732561 having 5.0 to $12.1 \mathrm{~mm}$ and women $6.9-16.5 \mathrm{~mm}$. The distance between the origin of the superior mesenteric artery and right renal artery was ranging between 6.2 to $23.5 \mathrm{~mm}$, in males being 6.5 to $19.1 \mathrm{~mm}$ and in women from 6.2 to $235 \mathrm{~mm}$. The distance between the origin of the superior mesenteric artery and left renal artery we found between 5.7 to $23.5 \mathrm{~mm}$, in males being 5.7 to $21.2 \mathrm{~mm}$, and in women from 6.2 to $235 \mathrm{~mm}$. The distance between the aortic origin of the superior and inferior mesenteric arteries was ranging between 50.6 to $91.2 \mathrm{~mm}$, in males being 50.6 to $91.2 \mathrm{~mm}$ and in women from 58.2 to $88.4 \mathrm{~mm}$.

Keywords: superior mesenetric artery, morphological features

\section{Introduction}

Through its branches, superior mesenteric artery distributes itself to a portion of the duodenum, small bowel, cecum, appendix, ascending colon and the first $2 / 3$ of the transverse colon, a portion of the pancreas, the entire mesentery and a portion of the transverse mesocolon, frequently participating to the liver vascularization through a right hepatic artery which may arise from the superior mesenteric artery. From the origin, the artery is directed inferiorly, on about 3 $\mathrm{cm}$, applied to the ventral wall of the aorta, behind the isthmus of the pancreas, then is directed in an acute angle away from the aorta on the inferior margin of the pancreas, descends diagonally from the uncinate process and the third portion of the duodenum, which crosses it vertically. Then it penetrates the root of the mesentery whose trajectory and direction follows for a 
few centimeters and engages in the floating part of the latter, where it ends. To determine its vascularization territory the following are important to be known: the artery origin from the abdominal aorta, establishing the existing relationships with other branches, particularly digestive aortic branches. It must be determined endolumenal orifice characteristics, especially morphometric features, blood volume having a major importance on the vascularization territories; not least, origin and anatomical features of its collateral branches which depend on the arterial path, in conjunction with the angle which the artery makes with the aorta.

\section{Material and methods}

Our study was conducted on a total of 46 $\mathrm{CT}$ angiographies, performed on a GE LightSpeed VCT 64-slice CT installation being in service of medical imaging center Pozimed Constanta. The following features were followed: origin of the superior mesenteric artery related to the vertebral spine, endolumenal arterial ostium dimensions, the angle between aorta and superior mesenteric artery at its origin and the distance between the origin of the artery and the celiac trunk, renal arteries ( right and left) and inferior mesenteric artery. Benchmarks were followed in relation to the gender of the person examined and we specify that these guidelines were not always determined on the same number of cases, either because of existence of a celiomesenteric trunk, either due to the presence of two renal arteries.

\section{Results}

The origin of the superior mesenteric artery relative to the spine was followed on 46 cases, of which 24 female cases $(52.17 \%)$ and 22 male cases $(47.83 \%)$ (Figure 1). In 43 cases $(93.48 \%)$ superior mesenteric artery originated directly from the abdominal aorta, whereas in 3 cases $(6.52 \%)$ it was originating in a celiomesenteric trunk all three cases being of males, in which case the origin of the mesenteric artery depends on the direction of origin trunk (Figure 2). In cases in which the superior mesenteric artery originated from the abdominal aorta, the origin of the artery was located between T12 vertebra and L1-L2 intervertebral disc.

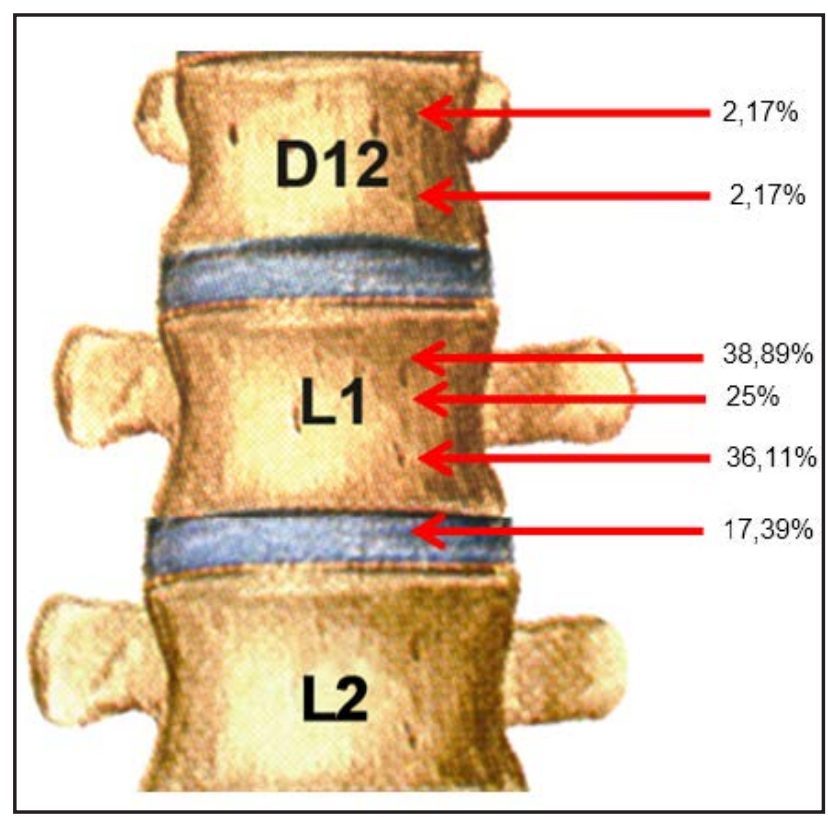

Figure 1. Superior mesenteric artery origin related to the spine

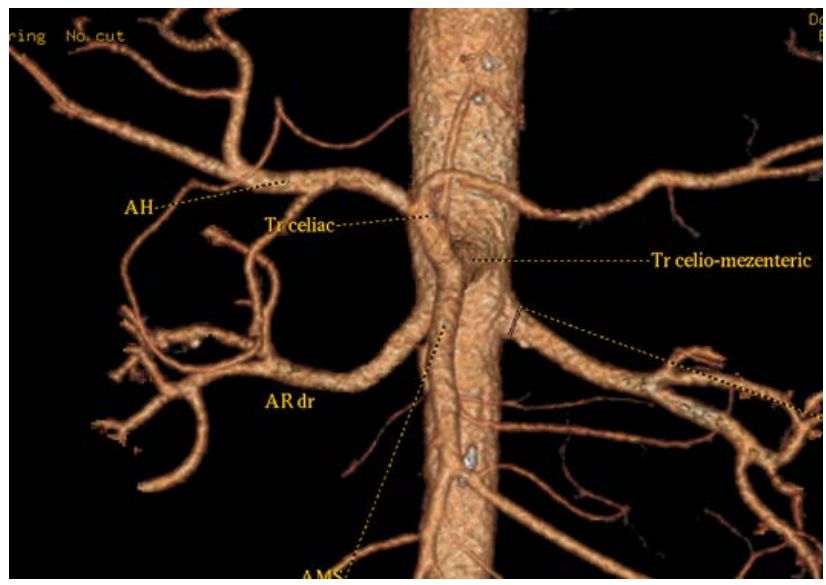

Figure 2. Superior mesenteric artery origin from celiomesenteric trunk (male case). 
The T12 vertebra origin was found in 2 cases $(4.35 \%)$, in a particular case at the level of the upper $1 / 2$ of the vertebral body, closer to its middle (Figure 3 ), and in the other case in the lower $1 / 2$ of the vertebra, closer to the inferior edge.

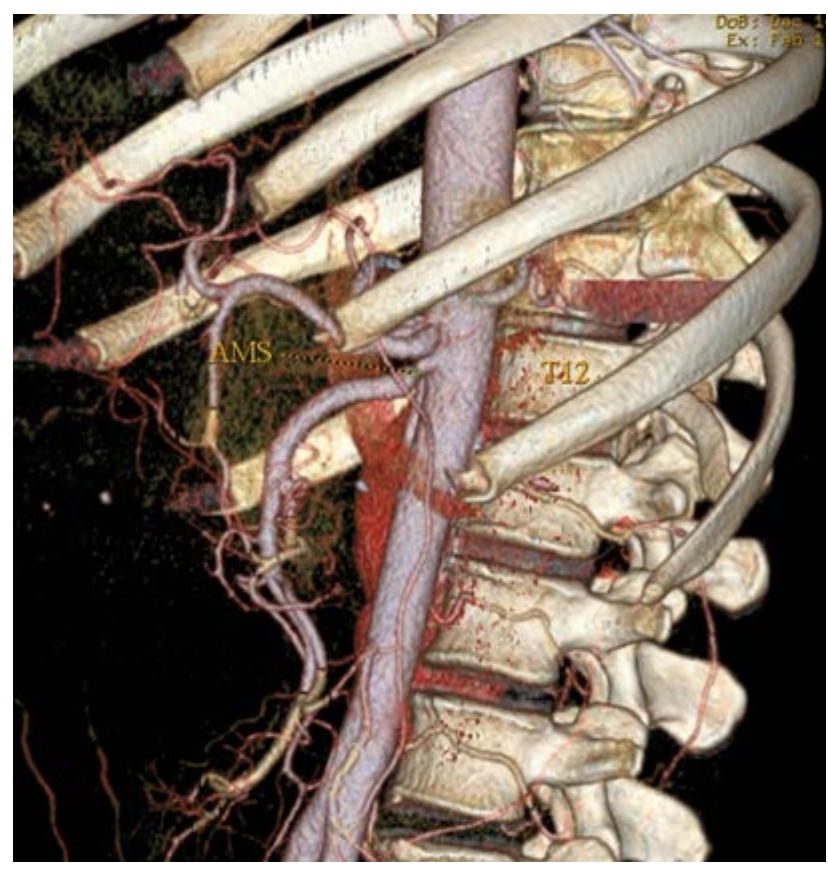

Figure 3. Superior mesenteric artery origin at the level of upper $1 / 2$ of 112 vertebra, nearest of its middle (female case).

The superior mesenteric artery originated at the level of L1 in 36 cases (78.26\%), finding three variants. In 14 cases $(38.89 \%)$ the artery origin was located at the upper $1 / 2$ of the vertebra L1, describing another three possibilities: 4 cases $(11.11 \%)$ at the upper edge of the vertebra; in 6 cases $(16.67 \%)$ closer to the upper edge of the vertebra and in 4 cases $(16.67 \%)$ closer to the middle vertebra. In 9 cases $(25 \%)$ the origin of the mesenteric artery was located at the middle of L1 (Figure 4), and in 13 cases $(36.11 \%)$ at the bottom $1 / 2$ of the vertebra embodiment with three aspects: 8 cases $(22.22 \%)$ the origin was located close to the middle vertebra, in 4 cases $(11.11 \%)$ closer to the lower edge of the vertebra and in one case $(2.78 \%)$ at the inferior margin of vertebra.

In 8 cases $(17.39 \%)$ the origin of the superior mesenteric artery was located at the L1-L2 intervertebral disc (Figure 5).

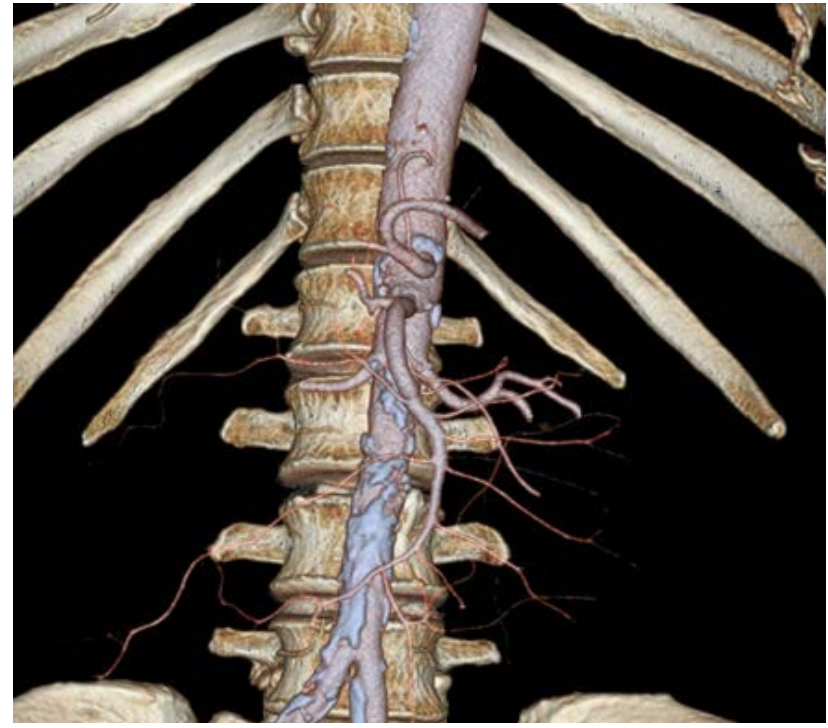

Figure 4. Superior mesenteric artery origin at the level of middle L1 vertebra (male case).

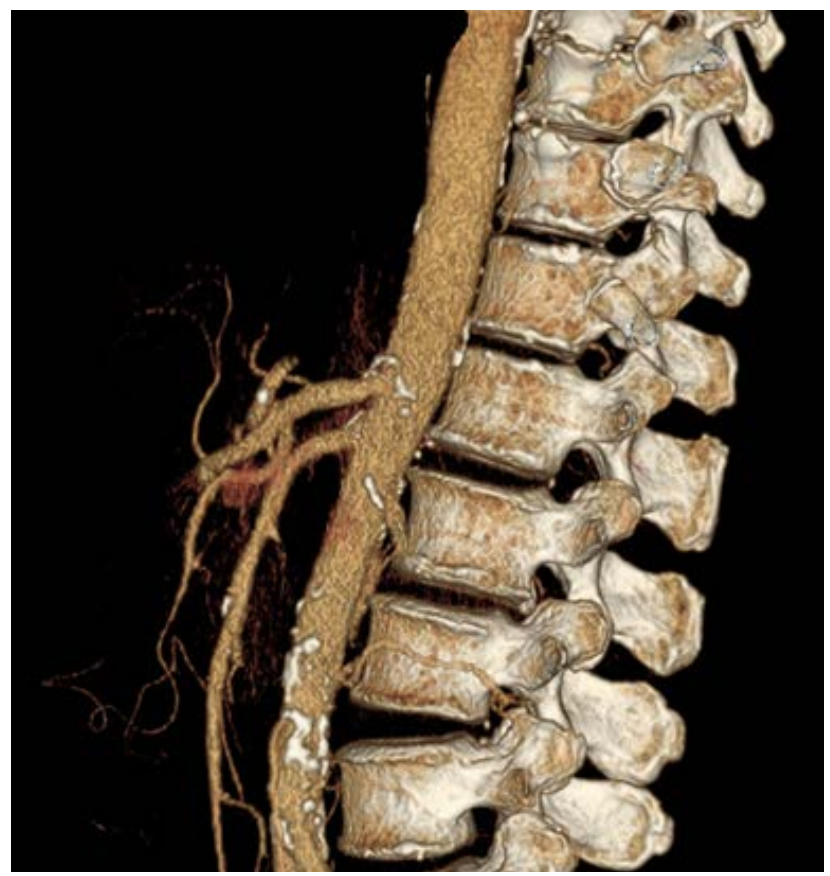

Figure 5. Superior mesenteric artery origin at L1-L2 intervertebral disc level (female case).

In males, at the level of L1 had their origin 20 of the superior mesenteric arteries $(90.91 \%$ of male cases), at the upper $1 / 2$ originating a number of 6 arteries: two cases at the upper edge (9.09\%), 2 
cases closer to the top $(9.09 \%)$ and another 2 cases closer to the middle of the vertebra $(9.09 \%)$. At the middle of L1 had their origin 6 arteries $(27.27 \%)$ and 8 cases $(36.36 \%$ ) had their origin in the lower $1 / 2$ of the vertebra, in each 4 cases $(18.18 \%)$ closer to the middle vertebra, and closer to the bottom edge of the L1 vertebra respectively. In 2 male cases $(9.09 \%)$ superior mesenteric artery originated at the level of L1-L2 intervertebral disc.

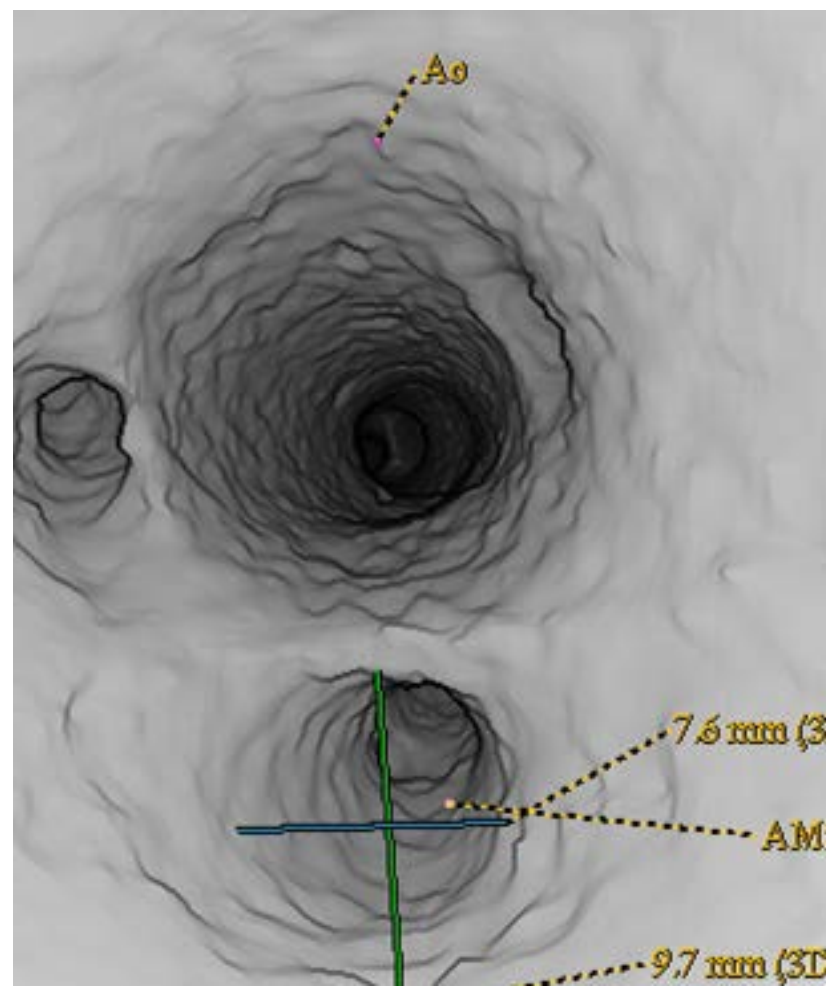

Figure 6. Endolumenal diameters of superior mesenteric artery orifice, $9.7 \mathrm{~mm}$ vertical and $7.6 \mathrm{~mm}$ horizontal (male case).

In women, in 2 cases $(8.33 \%)$ the origin of superior mesenteric artery was located at the level of T12-L1 intervertebral disc. In 16 cases $(66.67 \%)$, the artery origin was located at the L1 vertebra level. In the upper $1 / 2$ of the vertebra 8 arteries had their origin $(33.33 \%)$, with three variants: two cases $(8.33 \%)$ at the upper edge, 4 cases $(16.67 \%)$ closest to the upper edge and two cases $(8.33 \%)$ closer to the middle of the vertebra. In 3 cases $(12.5 \%)$ superior mesenteric artery originated at the mid vertebra, and in 5 cases $(8.33 \%)$ the origin was located in the lower
$1 / 2$ showing two variants: in 4 cases $(16.67 \%)$ closer to the center and in a case on the lower edge of the vertebra $(4.17 \%)$.

Endoaortic orifice of the superior mesenteric artery was studied in terms of its shape and dimensions, determining vertical and horizontal diameters and differences between them.

Vertical diameter was followed in a total of 48 cases, 22 cases were males $(45.83 \%)$ and 26 cases females $(51.17 \%)$. Its dimensions were between 5.6 to $10.9 \mathrm{~mm}$, so between the minimum and the maximum there is a difference of $5.3 \mathrm{~mm}$. Males had a vertical diameter size ranging from 6.9 to 10.9 $\mathrm{mm}$, extreme dimensions were found each in one single case $(4.55 \%) .7$ cases $(31.82 \%)$ had a diameter between 7.3-7.8 $\mathrm{mm}$, in another 7 cases $(31,82 \%)$ 9.2 to $9.9 \mathrm{~mm}$, and in six cases $(27.27 \%)$ the vertical diameter was between 8.5 to $8.8 \mathrm{~mm}$. In women the vertical diameter was found between 5.6 to $8.6 \mathrm{~mm}$, $5.6 \mathrm{~mm}$ dimension finding it in two cases $(7.69 \%)$. Most commonly, in 17 cases $(65.38 \%)$ the size ranged between 6.0-6.8 mm, in four cases $(15.38 \%$ ) had 7.3$7.8 \mathrm{~mm}$, and in 3 cases $(11.58 \%$ ) between 8.0 to 8.6 $\mathrm{mm}$

Horizontal diameter of the endoartic orifice of superior mesenteric artery was followed on a number of 50 cases, 22 cases being males (44\%) and 28 cases women (56\%), ranging between 4.9 and $9.7 \mathrm{~mm}$. The difference between the minimum and the maximum diameter is $4.8 \mathrm{~mm}$. In males, the dimensions we found were between 6.4 and $9.7 \mathrm{~mm}$. The values 6.2-6.4 $\mathrm{mm}$, and 9.1-9.7 $\mathrm{mm}$, were found each in 4 cases $(18.18 \%)$. In 6 cases $(27.27 \%)$ had a horizontal diameter of 7.1 to $7.9 \mathrm{~mm}$, and in 8 patients $(36.36 \%)$ was 8.3 to $8.9 \mathrm{~mm}$. In women, we found horizontal diameter between 4.9 to $8.3 \mathrm{~mm}$, the size of $4.9 \mathrm{~mm}$ being found only in one case $(3.57 \%)$. In 4 cases $(14.29 \%)$ horizontal diameter was between 5.2-5.5 $\mathrm{mm}$, in 12 cases $(42.86 \%)$ the values ranged between 6.0 to $6.9 \mathrm{~mm}$, in 8 patients $(28.57 \%)$ the values were 7.1-7.7 $\mathrm{mm}$ and in 3 cases (10.71\%) the diameter was 8.0 to $8.3 \mathrm{~mm}$.

Comparing the two diameters, we found that the vertical diameter was larger in 26 cases $(54.17 \%)$ with differences between 0.1 to $2.4 \mathrm{~mm}$ and in 22 cases $(45.83 \%)$ the largest diameter was the horizontal, with differences of 0.1 to $2.2 \mathrm{~mm}$. Vertical 
diameter in males was higher in 13 cases $(59.09 \%)$, with differences of 0.1 to $2.4 \mathrm{~mm}$ (Figure 6) and in 9 cases $(40.91 \%)$ the horizontal diameter was larger, the difference being between 0.1 to $2.1 \mathrm{~mm}$. Vertical diameter in women was higher in 13 cases $(50 \%)$, with differences of $0.1-2.0 \mathrm{~mm}$, and in the other 13 cases $(50 \%)$ the horizontal diameter dominates, with differences contained between 0.1 to $2.2 \mathrm{~mm}$.

The angle that the superior mesenteric artery makes it with the aortic wall was studied on a number of 43 cases, 19 male cases (44.19\%) and 24 cases of females $(55.18 \%)$. The value of the angle was found between 16.6-120, 8o, most commonly, in 11 cases $(45.83 \%)$, the value being of $50.2-58,40$. In males, the angle ranged between $24.8-120,8 \mathrm{o}$, the value of 24,8 o finding it in one case $(5.26 \%)$. The women had an angle value of $16.7-120,80$ (Figure 7), the value of $120,8 \mathrm{o}$ finding it in only one case $(2.33 \%)$, most commonly, in 11 cases $(25.58 \%)$, the values between $50.2-58,4$ o being met.

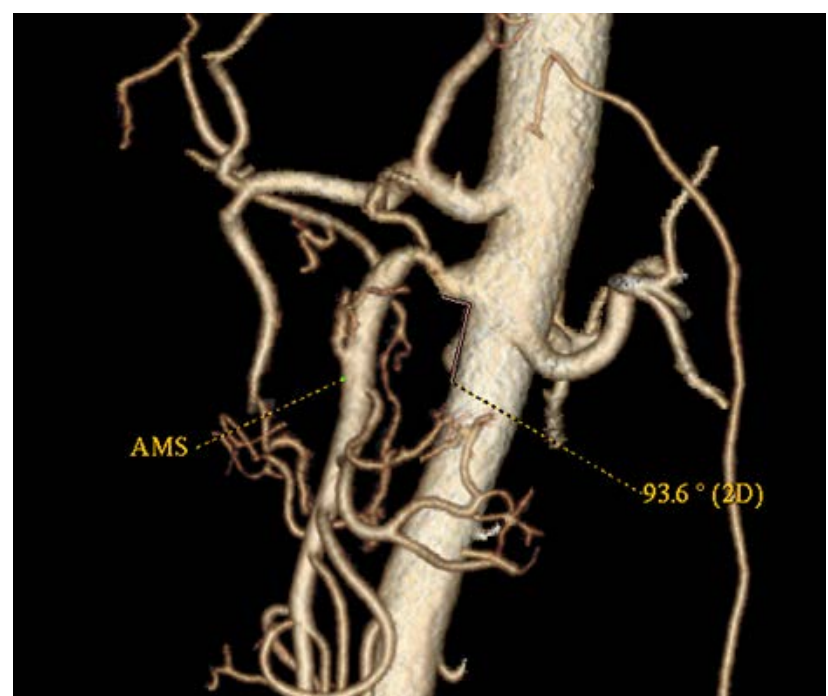

Figure 7. Aorto-mesenteric angle of 93,6o (female case).

The distance between the aortic origins of the superior mesenteric artery and celiac trunk, was investigated on 38 cases. We found a general distance of 5.0 to $16.5 \mathrm{~mm}$, most commonly, in 14 cases $(36.84 \%)$, the distance was of 7,0-8,5 $\mathrm{mm}$. In males the distance was $5,0-12.1 \mathrm{~mm}$, in $50 \%$ of cases being a distance of 7,0-8,6 mm (Figure 8). In women the distance was between $6.9-16,5 \mathrm{~mm}$, the
$16.5 \mathrm{~mm}$ distance being met in one case $(2.63 \%)$, most frequently meeting the distance of $6.9-8.6 \mathrm{~mm}$ (36.36\%) followed by the distance between 11.5-13.6 $\mathrm{mm}(31.82 \%)$ and distance of $9.0-10,0 \mathrm{~mm}(27.27 \%)$.

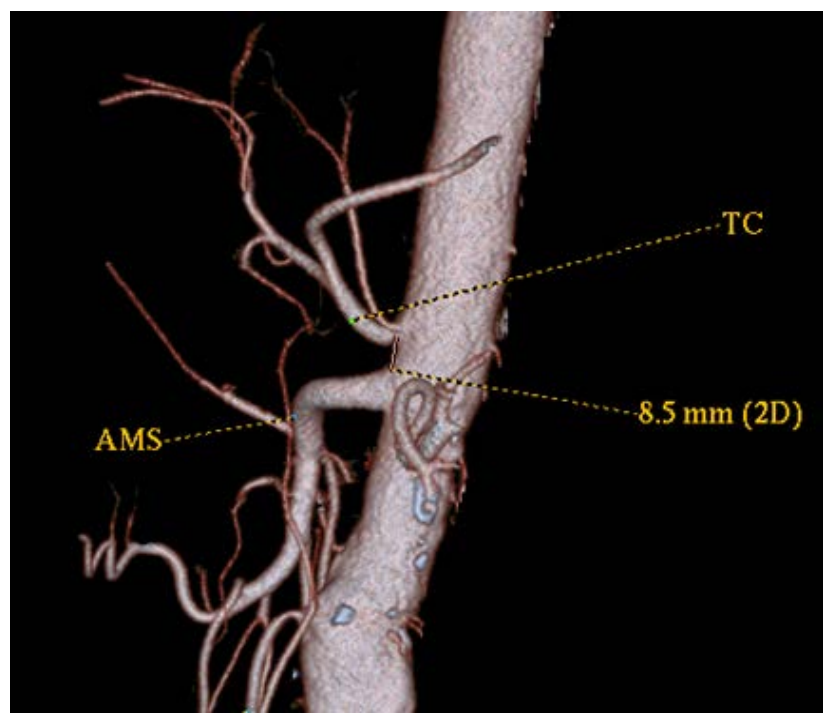

Figure 8. Distance of $8.5 \mathrm{~mm}$ between superior mesenteric artery and celiac trunk (male case).

The distance between the origin of the superior mesenteric artery and renal artery, studied on 36 cases, we found it between $6.2-23.5 \mathrm{~mm}$, the 23.5 $\mathrm{mm}$ distance being in only one case $(2.78 \%)$, the most common being the distances of $6.2-8.9 \mathrm{~mm}(30.56 \%)$ and $14.3-16.2 \mathrm{~mm}(27.78 \%)$. In males the distance was $6.5-19,1 \mathrm{~mm}, 19.1 \mathrm{~mm}$ being found in one case $(8.33 \%)$, meeting a distance of $6,5-9 \mathrm{~mm}$ in $50 \%$ of cases, and the distance of $11.5-14.5 \mathrm{~mm}$ in $41.67 \%$ of cases. In females the distance between the two origins were between $6.2-23.5 \mathrm{~mm}$, with $23.5 \mathrm{~mm}$ distance in one case (4.17\%). Distances of 6,2-9,7 mm were met in $37.5 \%$ of cases, in $33.33 \%$ of cases the distance was 14.7 to $16.2 \mathrm{~mm}$ and in $25 \%$ of cases of 10.2 $11.8 \mathrm{~mm}$. 


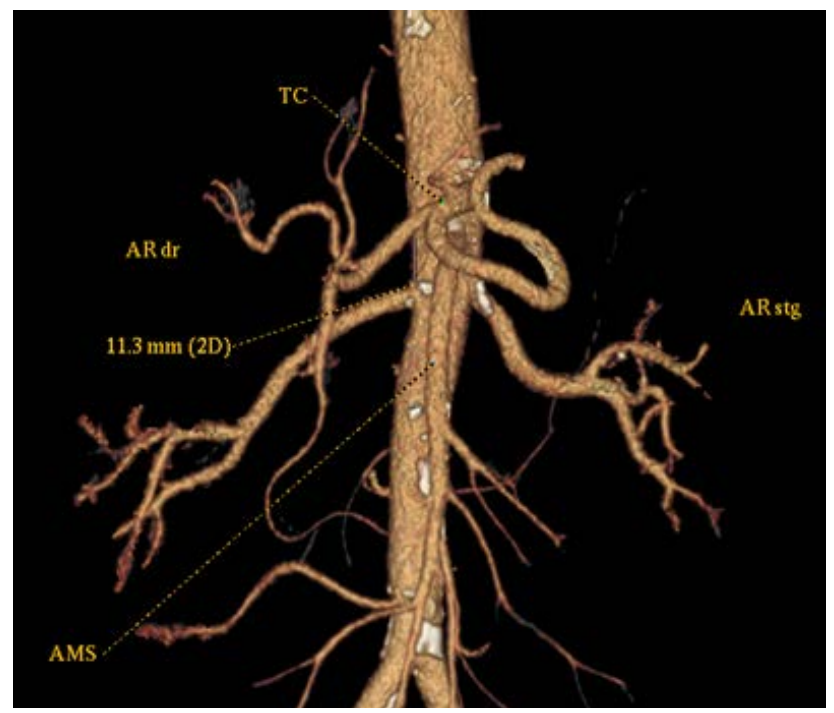

Figure 9. Distance of $11.3 \mathrm{~mm}$ between superior mesenteric artery and left renal artery (female case).

The distance between the origins of the superior mesenteric artery and the left renal artery, studied on 32 cases, we found it between $5.7-23.5 \mathrm{~mm}$, the $23.5 \mathrm{~mm}$ distance meeting it in one case $(3.12 \%)$, the most common being the distances from 13.3-14,2 $\mathrm{mm}(34.37 \%)$ and $18.3-18.7 \mathrm{~mm}(25 \%)$. In males the distance was of 5.7-21.2 $\mathrm{mm}$, distances of $5.7 \mathrm{~mm}$ and $21.2 \mathrm{~mm}$ being found each in a single case $(8.33 \%)$, and in every other $41.67 \%$ of cases the distances were 13.5-15.3 $\mathrm{mm}$ and $18.3-18.7 \mathrm{~mm}$ respectively. In the female sex distances were found between 6.2-23.5 $\mathrm{mm}$ (Figure 9), with the $23.5 \mathrm{~mm}$ distance being met in one case $(4.17 \%)$. Most commonly this distance was $13.3-14,2 \mathrm{~mm}(40 \%)$, followed by $16.2-18.4 \mathrm{~mm}$ (35\%) and 6,2-10.3 $\mathrm{mm}(20 \%)$.

The distance between the origins of superior and inferior mesenteric arteries, studied on a number of 38 cases, were found to range between 50.6-91,2 $\mathrm{mm}$. The distance of $91.2 \mathrm{~mm}$ was in a single case $(2.63 \%)$, the most common being the distance 62.3$69,4 \mathrm{~mm}(36.84 \%)$, followed by the distance of 73.5 $76.8 \mathrm{~mm}(23.68 \%)$, the distance of $50.6-59.9 \mathrm{~mm}$ $(21.05 \%)$ and the distance of $81.5 \mathrm{~mm}-88,4(15.79 \%)$. In males the distances were between $50.6-91,2 \mathrm{~mm}$ (Figure 10), with distance of $91.2 \mathrm{~mm}$ in a single case (6.25\%). The most common distances were 50.9-59.9 $\mathrm{mm}(37.5 \%)$ and $75.0-76,2 \mathrm{~mm}(31.5 \%)$. In female sex we found a distance between 58.2-88,4 mm, the distance $58.2 \mathrm{~mm}$ being met in one case $(4.55 \%)$, the most common being the distance62.3-69,4 mm $(54.55 \%)$.

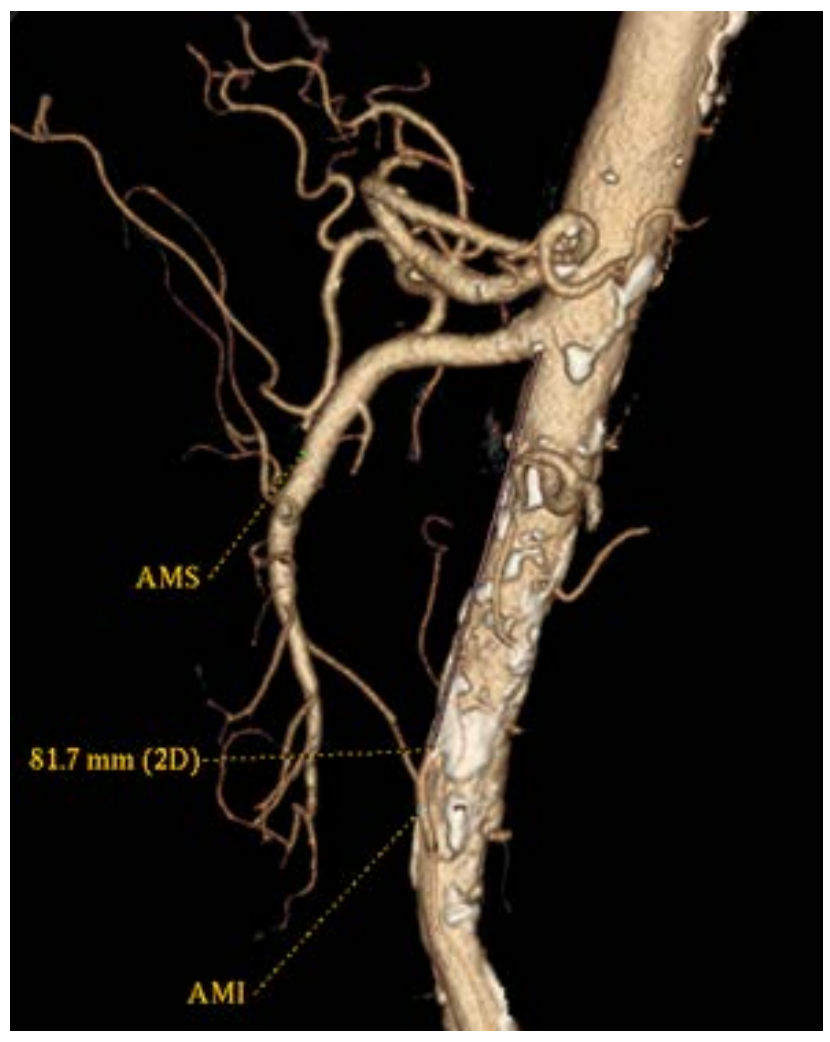

Figure 10. Distance of $81.7 \mathrm{~mm}$ between superior and inferior mesenteric arteries (male case).

\section{Discussions}

Comparing our results obtained in respect of the origin of the superior mesenteric artery related to the spine, it is found that most authors $[1,2,3$, $4,5]$ indicate the L1 vertebra, without making any other clarifications, [6] indicating the upper edge of L1. [7 and 8] localise the origin of the artery at the level of the upper edge of L1 or at level of T12-L1 intervertebral disc and [9] locates it at the level of L1-L2 intervertebral disc. [10] sets the origin of the 
superior mesenteric artery at $1-2 \mathrm{~cm}$ below the origin of the celiac trunk, which locate it at the bottom of the body of the T12 (Table I).

Table I. The origin of the superior mesenteric artery in relation to the vertebral spine compared with literature data

\begin{tabular}{|l|l|}
\hline Author & Superior mesenteric artery origin level \\
\hline Rouvière & $\begin{array}{l}\text { Upper border L1 or T12-L1 intervertebral } \\
\text { disc }\end{array}$ \\
\hline Gray & Intervertebral disc L1-L2 \\
\hline Paturet & $\begin{array}{l}\text { Upper } 1 / 2 \text { of L1 vertebral body or T12-L1 } \\
\text { intervertebral disc }\end{array}$ \\
\hline Kamina & Upper border L1 \\
\hline Pillet & L1 \\
\hline Moore & L1 \\
\hline Schünke & L1 \\
\hline Sakher & L1 \\
\hline Paris & L1 \\
\hline $\begin{array}{l}\text { Personal } \\
\text { cases }\end{array}$ & $\begin{array}{l}\text { L1: 78,26\%; } \\
\text { intervertebral disc L1-L2: 17,39\% } \\
\text { T12: } 4,35 \%\end{array}$ \\
\hline
\end{tabular}

In the literature we consulted it is not specified the origin of the superior mesenteric artery according to gender. We have found that the origin of the superior mesenteric artery is more common at the level of the L1 in males with a difference of $24.24 \%$ cases, in females the L1-L2 intervertebral disc being more frequent with $7.61 \%$ cases. We encountered only in females the origin at the level of T12 vertebra.

In regard to the dimensions of the endoaortic orifice of the superior mesenteric artery, the results show us that it is always oval shaped, under no circumstances equal horizontal and vertical diameters being equal. In $54.17 \%$ of cases the orifice was oval shaped due to a large vertical axis, and in $45.83 \%$ the horizontal axis was bigger. In male sex endolumenal orifice with higher vertical axis was more common than the female sex with $9.09 \%$ of cases, in women being more commonly encountered endoaortic oval shaped orifice with large horizontal diameter again with $9.09 \%$ of cases.

The angle formed by the abdominal aorta and superior mesenteric artery, is lower in $25.58 \%$ of cases, with values between $16.70-39,80$, most often being between 50, 2o -95, 9o (62.79\%). After [8], this angle is of $15-20^{\circ}$, so the maximum value found is greater than 75,90 than the one given by [8]. In males this angle was higher than the females, with a difference of $8.1 \mathrm{~mm}$ for the minimum values and $27.2 \mathrm{~mm}$ for the maximum ones.

The distance between the superior mesenteric artery and the celiac trunk had a difference of $11.5 \mathrm{~mm}$ between the minimum and maximum. The minimum value of this distance is less than $5 \mathrm{~mm}$ versus [2, $6,10]$ and $3 \mathrm{~mm}$ versus [8]. The maximum value is higher with $6.5 \mathrm{~mm}$ compared with $[2,6,7,8,9]$ and less with $3.5 \mathrm{~mm}$ versus [10], without founding a maximum distance higher than $16.5 \mathrm{~mm}$ in our cases, this distance being met only in a single female case (Table II). The distance between the two arteries was higher in women, with $1.9-4,4 \mathrm{~mm}$, but taking into account the fact that the maximal difference was met only in one case, we can consider that this distance was between 1,5-1,9 $\mathrm{mm}$.

Table II. The distance between the origin of the superior mesenteric artery and the celiac trunk.

\begin{tabular}{|l|l|}
\hline Author & $\begin{array}{l}\text { Superior mesenteric artery-celiac } \\
\text { trunk distance (mm) }\end{array}$ \\
\hline Testut & $10-20$ \\
\hline Rouvière & 10 \\
\hline Gray & 10 \\
\hline Paturet & $8-10$ \\
\hline Pillet & 10 \\
\hline Kamina & 10 \\
\hline Personal cases & $5-16,5 \quad \begin{array}{l}\text { M: } 5-12,1 \\
\end{array}$ \\
\hline
\end{tabular}

The distance between the superior mesenteric artery and the right renal artery presented with a difference of $17.3 \mathrm{~mm}$ between minimum and maximum values. In males this difference was of 12.4 $\mathrm{mm}$ and in females $17.3 \mathrm{~mm}$, so larger than males with $4.9 \mathrm{~mm}$.

The distance between the superior mesenteric artery and the left renal artery had a difference of 17.8 $\mathrm{mm}$ between the minimum and maximum values. In males this difference was of $15.5 \mathrm{~mm}$, whereas in 
females of $17.3 \mathrm{~mm}$, so larger than males with 1.8 $\mathrm{mm}$, but considering the fact that maximum distances of males $(21.2 \mathrm{~mm})$ and females $(23.5 \mathrm{~mm})$ we've just met in a single case, this difference is in fact only 0.3 $\mathrm{mm}$. In the consulted literature $[2,10]$, the superior mesenteric artery has an origin a little bit above that of the renal arteries.

The distance between the origins of superior and inferior mesenteric artery presented with a difference of $40.6 \mathrm{~mm}$ between minimum and maximum values. This difference was met in male cases, whereas in females was $30.2 \mathrm{~mm}$, so less with $10.4 \mathrm{~mm}$. [8] gives this distance of $80-100 \mathrm{~mm}$, our maximum value in our cases being $91.2 \mathrm{~mm}$, so shorter with $8.8 \mathrm{~mm}$.

\section{Conclusions}

The study we carried out show that, relative to the spine, superior mesenteric artery has a relative constant origin, in most cases being localized at different levels of the L1 vertebra in $78.26 \%$ of cases, particularly in women where the percentage found is $90.91 \%$ of cases. In connection with the morphological characteristics of the superior mesenteric artery endolumenal orifice, we mention that these aspects are described less in the literature and therefore our results are a novelty in this regard. We found that there is a natural connection between the angle that the superior mesenteric artery emerges from the aorta and the path that the artery will follow later. The definition of these morphological landmarks showed that there are gender differences, sometimes significant. It is certain that any statistical differences arising between authors depend on the number of cases, but also on the geographic area, sex and working methods, in imaging studies measurements are made electronic and therefore more accurate, being carried on an active human body.

\section{References}

1. Moore K. \& Dalley A. (2001). Anatomie mèdicale. Aspects fondamentaux et applications cliniques. Ed. De Boeck Université, Bruxelles, 244-245

2. Pillet J. (1994). L'aorte abdominale et ses branches. In: Chevrel JP, Anatomie clinique, Le tronc, (pp 429-430). Paris: Ed. Springer-Verlag France

3. Schünke M., Schulte E., Schumacher U., Voll M. \& Wesker K. (2005). Atlas d'Anatomie Humaine. Prométhée. Cou et organes internes. (pp 264271). Paris: Ed. Maloine

4. Sakher H.A.S. (2009). Particularități morfologice ale vascularizaţiei colonului. Teză de doctorat, Constanţa

5. Paris S. (2006). Anatomia morfofuncţională a arterei mezenterice superioare. Teză de doctorat, Constanța

6. Kamina P. (2007). Anatomie clinique. Tome 3. Thorax. Abdomen. (pp 142-147). Ed. Maloine.

7. Rouvière H. \& Delmas A. (1997). Anatomie humaine,. Descriptive, topographique et fonctionnelle. Tome 2. Tronc. ( $\mathrm{pp}$ 177-195). Paris:Ed. Masson.

8. Paturet G. (1964) - Traité d'Anatomie Humain (pp. 453-542), Paris:Ed. Masson.

9. Standring S. (2005). Gray's Anatomy. The Anatomical Basis of Clinical Practice. (pp 1117-1120). Edinburg :Ed. Elsevier- Churchill Livingstone.

10. Testut L. (1924) - Traité d'Anatomie Humaine, Angeiologie (pp. 193-206) Paris: Ed. Gaston Doin. 